Article

\title{
An Analysis of Peer-Reviewed Publications on Open Educational Practices (OEP) from 2007 to 2020: A Bibliometric Mapping Analysis
}

\author{
Ahmed Tlili ${ }^{1, * \mathbb{D}}$, Daniel Burgos ${ }^{2, * \mathbb{D}}$, Ronghuai Huang ${ }^{1}$, Sanjaya Mishra ${ }^{3} \mathbb{D}$, Ramesh Chander Sharma $4 \mathbb{D}^{\mathbb{D}}$ \\ and Aras Bozkurt ${ }^{5,6}$ (D)
}

check for

updates

Citation: Tlili, A.; Burgos, D.; Huang, R.; Mishra, S.; Sharma, R.C.; Bozkurt,

A. An Analysis of Peer-Reviewed

Publications on Open Educational Practices (OEP) from 2007 to 2020: A Bibliometric Mapping Analysis. Sustainability 2021, 13, 10798. https:/ / doi.org/10.3390/su131910798

Academic Editor: Massimo Aria

Received: 28 August 2021

Accepted: 24 September 2021

Published: 28 September 2021

Publisher's Note: MDPI stays neutral with regard to jurisdictional claims in published maps and institutional affiliations.

Copyright: (c) 2021 by the authors. Licensee MDPI, Basel, Switzerland. This article is an open access article distributed under the terms and conditions of the Creative Commons Attribution (CC BY) license (https:// creativecommons.org/licenses/by/ $4.0 /)$.
1 Smart Learning Institute, Beijing Normal University, Beijing 100875, China; huangrh@bnu.edu.cn

2 Research Institute for Innovation \& Technology in Education (UNIR iTED), Universidad Internacional de La Rioja (UNIR), 26006 Logroño, Spain

3 Commonwealth of Learning, Burnaby, BC V5H 4M2, Canada; smishra.col@gmail.com

4 Instructional Design Department, Dr. B. R. Ambedkar University Delhi, Delhi 110016, India; rc_sharma@yahoo.com

5 Distance Education Department, Open Education Faculty, Anadolu University, 26470 Eskişehir, Turkey; arasbozkurt@gmail.com

6 Department of English Studies, College of Human Sciences, University of South Africa (UNISA), Pretoria 0003, South Africa

* Correspondence: ahmed.tlili23@yahoo.com (A.T.); daniel.burgos@unir.net (D.B.)

\begin{abstract}
This study undertook a bibliometric mapping analysis of research papers on Open Educational Practices (OEP) in the Web of Science and Scopus databases. This study functions as a guide for new research, serving to identify trends in the OEP field and compare the existing research so as to identify gaps and promising future paths. A total of 635 studies were obtained; however, only 156 were finally selected for the analysis. VOSviewer software was used to identify the most frequently used keywords and terms in the abstracts and titles. This software was also used to analyse the studies for co-authorship and citations. The findings showed that research on OEP started in 2007 and focused on higher education, including open and distance higher education. Most of the OEP studies were published in English as journal articles, in particular, many were published in Distance Education, International Review of Research in Open and Distributed Learning, and Open Praxis. The United Kingdom, Spain, and Australia were the top contributors to the OEP literature. The analysis of keywords and terms in the titles and abstracts revealed that current OEP trends covered only open pedagogy and open collaboration, suggesting a need for more research on other trends, such as open assessment, open data, and open science. The results also suggested that future research needs to focus more on inclusive open educational practices that accommodate students with disabilities.
\end{abstract}

Keywords: open education; open educational practices; open educational resources; bibliometric mapping analysis; visualisation

\section{Introduction}

Open education can be described as a movement where knowledge can be freely accessed and (re)used; this can facilitate collaboration and provide innovative ways of learning that are different from the "simple linear forms" that today's textbooks present [1]. To foster open education, several scholars and organisations have called for developing Open Educational Resources (OER) to increase access to knowledge. The term OER was first coined at UNESCO's 2002 Forum on Open Courseware, and it was recently defined by UNESCO [2] as "learning, teaching and research materials in any format and medium that reside in the public domain or are under copyright that have been released under an open license, that permit no-cost access, re-use, re-purpose, adaptation and redistribution by others." Several studies have shown that OER can replace the conventional curriculum, 
hence reducing learning costs [3], as well as improving learning quality and ensuring inclusive education $[4,5]$.

With the rapid evolution of the open education movement, research has shifted from content-centred approaches that focus on educational resources (creation, sharing, etc.) to more practice-centred approaches that foster collaboration between learners and teachers for better learning outcomes [6]. In other words, researchers and educators have shifted their focus from simply creating and publishing OER to inventing innovative educational practices that can be implemented using OER. These are referred to as Open Educational Practices (OEP) "that involve students in active, constructive engagement with content, tools and services in the learning process, and promote learners' self-management, creativity and working in teams" [7] (p. 37). In another study, OEP are defined as "practices which support the (re)use and production of OER through institutional policies, promote innovative pedagogical models, and respect and empower learners as co-producers on their lifelong learning path" [8] (p. 12). Wiley and Hilton III [9] (p. 135) defined OEP as OER-enabled pedagogies, which are defined as a "set of teaching and learning practices that are only possible or practical in the context of the $5 \mathrm{R}$ (retain, reuse, revise, remix, and redistribute) permissions that are characteristic of OER." Ehlers [10] further emphasised that simple access to OER repositories in a traditional way is considered a content-centred approach rather than an OEP. Huang et al. [11] have reported innovative case studies of implementing OEP during the COVID-19 pandemic to enable innovative education from home.

Weller et al. [12] stated that the emergence of OEP as a distinct research theme is relatively new and is likely to continue growing. Koseoglu et al. [13] further pointed out that several critical questions in the OEP research theme are still unanswered, calling for further research. This study aimed to identify the research gaps regarding OEP and their possible future paths through a bibliometric mapping analysis of research studies on OEP in the Web of Science and Scopus databases. The bibliometric mapping analysis method was adopted mainly because it provides visual representations of the relationships between the main concepts [14]. Visualisation through mapping allows researchers to identify the background of a given research field, the relationships between key concepts, and possible future trends $[15,16]$. Several bibliometric analyses were already done to better understand some of the themes under the open education umbrella, including OER $[17,18]$ and massive open online courses [19]; however, to the best of our knowledge, the only study so far that used bibliometric analysis on the OEP research field was that of Koseoglu and Bozkurt [20], which covered only 53 studies found in Scopus. This study extended the current literature by mapping the research studies related to OEP, aiming for a systematic view of the main publications, sources of scientific information, authors, and geographical origin of the studies. More specifically, this study answered the following research questions:

RQ1. What is the distribution of OEP research studies in terms of publication year, document type, language, and publication venue in Web of Science and Scopus?

RQ2. Who are the major contributors to the OEP literature in Web of Science and Scopus?

RQ3. What are the most frequently used research methods and data collection techniques that are used by researchers regarding OEP?

RQ4. What are the most frequently used terms in the keywords, abstracts, and titles of OEP research studies in Web of Science and Scopus?

\section{Method}

This study involved a bibliometric mapping analysis, which uses both quantitative and statistical analysis to report the distribution patterns of the research articles on specific topics and from specific periods [21]. The analysis outputs are also visualised to better interpret the large volume of data such that this kind of study also benefits from qualitative analysis. The analysis of bibliometric data uses a systematic and reproducible process to review scientific publications, which involves using quantitative measures to evaluate research articles and identify their trends and patterns over a given period [22,23]. This 
analysis allows researchers to understand the literature and facilitate knowledge building by creating multiple types of associations between patterns, keywords, and references. This study followed the bibliometric analysis steps suggested by Zancanaro et al. [24]: (1) collecting, filtering, and data standardisation; and (2) analysis and synthesis of the collected data.

For the first step, while OEP are defined in various ways in the literature [25], this study used the most common keywords, namely, "open educational practices" OR "OEP". The search was performed in both Web of Science (WoS) and Scopus databases within titles and abstracts and without any period or document type specification. These databases are some of the largest databases of peer-reviewed scholarly literature [26]. The search was conducted on 20 December 2020. As a result, 635 studies were obtained. Out of these, 320 duplicated studies were omitted. The remaining 315 studies were filtered according to the following exclusion criteria. A study was excluded if (1) it did not go through peer review before publication (i.e., white papers, reports, handbooks, etc.), (2) it focused only on OER without discussing open educational practices that use OER, (3) it focused on open practices in other fields (e.g., economy), or (4) it could not be accessed online (i.e., the full text was not available). Based on these exclusion criteria, 156 articles were retained for the analysis. The filtering process was conducted by two researchers to ensure the reliability of the obtained findings. Through discussions, they reached a full consensus about the studies to be included. As the 156 articles were taken from two databases (WoS and Scopus), their metadata were standardised using a CSV file. The study selection process of this research is presented in Figure 1.

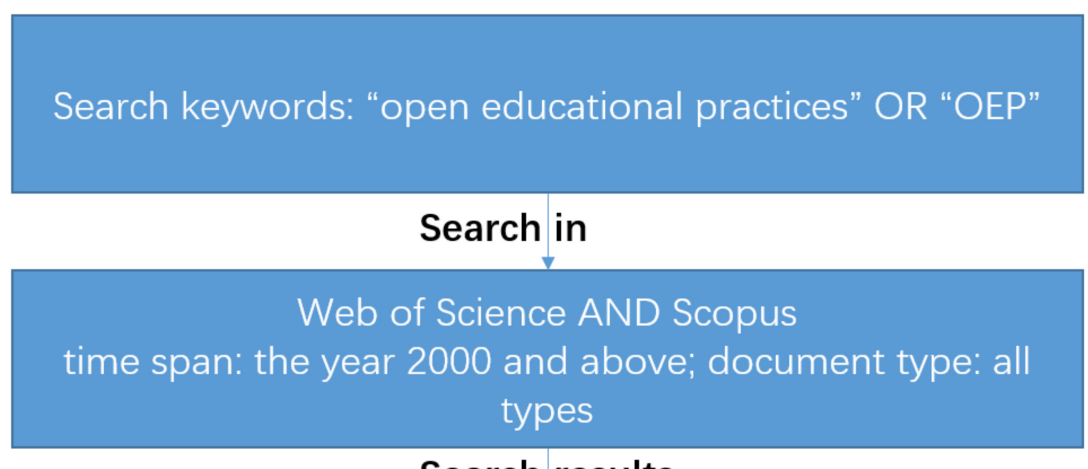

\section{Search results}

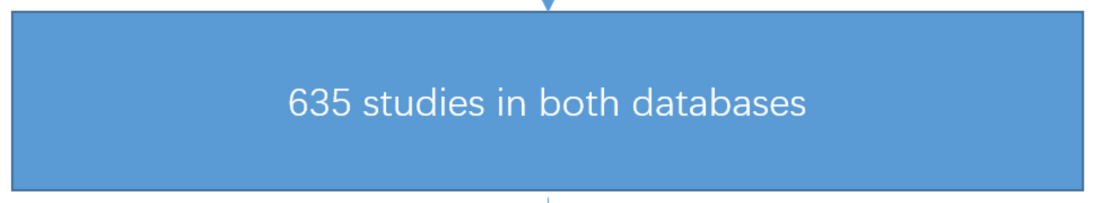

320 duplications were excluded

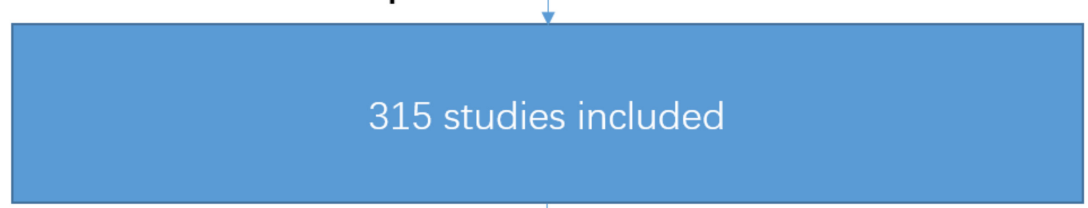

Filtering according to the inclusion/exclusion criteria

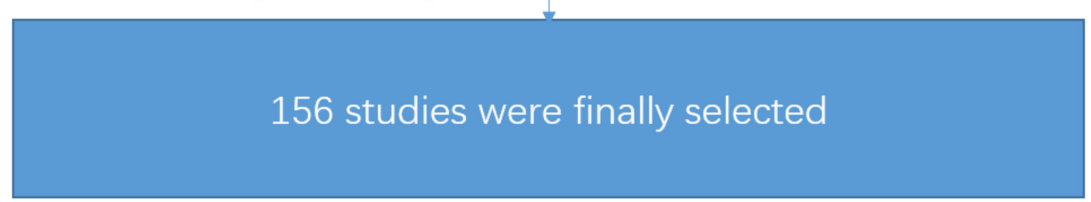

Figure 1. Flow chart for the article search and selection process.

For the bibliometric analysis and synthesis (second step), VOSviewer software was used to create distance-based co-occurrence maps, where the terms retrieved from key- 
words, titles, and abstracts were clustered and mapped according to their relatedness in a similarity matrix [27]. Table 1 shows the parameters that were adopted for the elaboration of the co-occurrence maps. The software was also used for co-authorship and citation analyses of the studies. The number of citations for each document was identified from each database where that document was found. In case the number of citations was missing, the Google Scholar citation number was used. VOSviewer software was used to analyse several scientific outputs in different scientific fields, such as inclusive education [28], tourism [29], and risk communication [30].

Table 1. Parameters that were adopted for the elaboration of the co-occurrence maps.

\begin{tabular}{cccccc}
\hline $\begin{array}{c}\text { Co-Occurrence } \\
\text { Network Map }\end{array}$ & $\begin{array}{c}\text { Minimum } \\
\text { Occurrence }\end{array}$ & $\begin{array}{c}\text { Cluster } \\
\text { Resolution }\end{array}$ & $\begin{array}{c}\text { Minimum } \\
\text { Cluster } \\
\text { Size }\end{array}$ & $\begin{array}{c}\text { Random } \\
\text { Starts }\end{array}$ & Iterations \\
\hline $\begin{array}{c}\text { Terms found in } \\
\text { keywords }\end{array}$ & 6 & 1.00 & 1 & 10 & 10 \\
$\begin{array}{c}\text { Terms found in titles } \\
\text { and abstracts }\end{array}$ & 10 & 1.00 & 1 & 10 & 10 \\
\hline
\end{tabular}

\section{Results}

3.1. What Was the Distribution of OEP Research Studies in Terms of Publication Year, Document Type, Language, and Publication Venue in the Web of Science and Scopus?

Figure 2 shows the number of published OEP studies by year. The first OEP study was published in 2007. Between 2007 and 2012, less than 20 studies on OEP were published in the WoS and Scopus. From 2012 onward, the yearly number of published studies on OEP significantly increased; the number peaked in 2017, decreased slightly by 2018 , and then peaked again in 2020 .

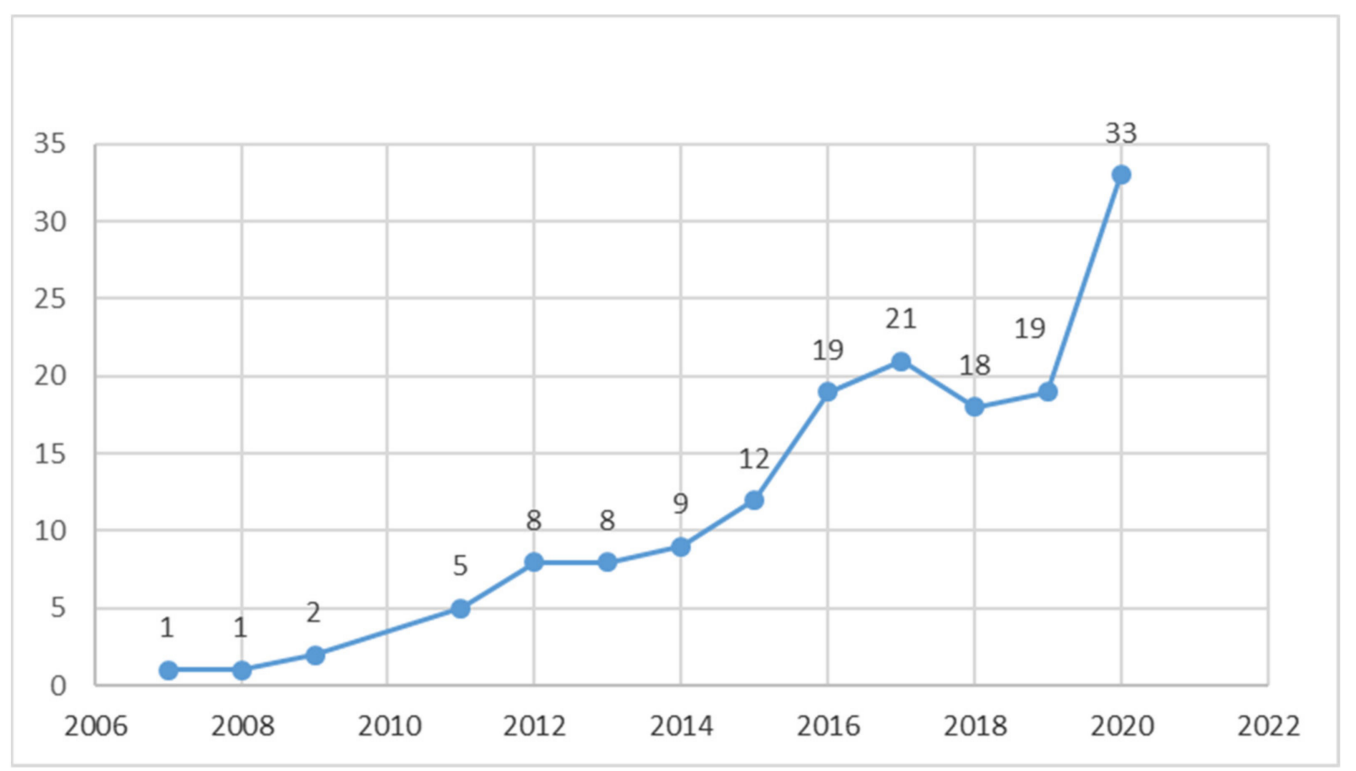

Figure 2. Distribution of OEP research studies by year of publication.

Figure 3 shows that $73 \%$ of the OEP research studies were published as journal articles. The rest were published as conference papers (16\%), book chapters $(8 \%)$, and editorial pieces (3\%). In terms of language, $88 \%$ of the studies were in English, $6 \%$ were in Spanish, and the rest were in French (2\%), Portuguese (2\%), Korean ( $1 \%)$, and Russian (1\%). Some of the studies were published in two languages, and therefore they were counted twice. 


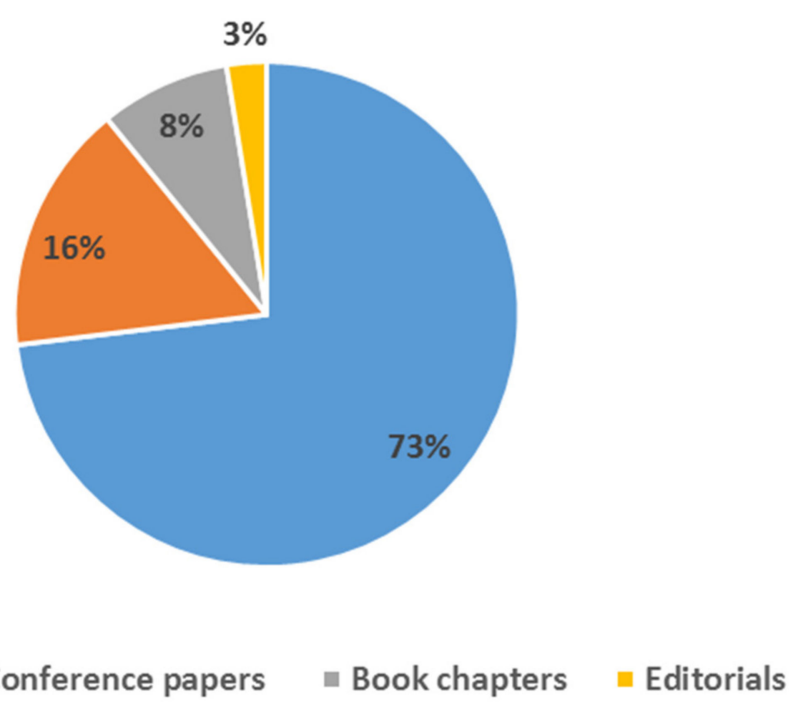

Figure 3. Distribution of OEP research studies by document type.

The OEP studies were distributed over 75 different publication venues. Table 2 lists the publication venues that had published at least three of the documents. It was found that the most prolific journals were Distance Education (18 documents), International Review of Research in Open and Distributed Learning (11 documents), Open Praxis (9 documents), and Journal of Interactive Media in Education (8 documents).

Table 2. Publication venues of OEP studies.

\begin{tabular}{ccc}
\hline Rank & Publication Venue & Documents \\
\hline 1 & Distance Education & 18 \\
2 & International Review of Research in Open and Distributed Learning & 11 \\
3 & Open Praxis & 9 \\
4 & Journal of Interactive Media in Education & 7 \\
5 & Book: Adoption and Impact of OER in the Global South & 6 \\
6 & RUSC Universities and Knowledge Society Journal & 4 \\
7 & Research in Learning Technology & 4 \\
8 & Alsic. Apprentissage des Langues et Systèmes d'Information et de Communication & 4 \\
10 & ASCILITE 2016 Conference Proceedings & 4 \\
11 & Journal of E-Learning and Knowledge Society & 4 \\
13 & Sustainability & 3 \\
& 3 \\
& Electronic Journal of e-Learning & 3 \\
\end{tabular}

\subsection{Who Were the Major Contributors to the OEP Literature in Web of Science and Scopus?}

The OEP studies came from 47 countries. Table 3 shows the top countries that contributed at least four documents. The United Kingdom published the most OEP research studies ( 38 documents), followed by Spain ( 21 documents), Australia (20 documents), and the United States of America (18 documents).

Figure 4 presents the co-authorship network by country. The colours represent cooperation clusters. This means that countries belonging to one cluster (shown in the same colour) cooperated more with each other than with countries in other clusters. The size of each circle represents the number of publications from that country. For instance, the United Kingdom has the biggest circle because it contributed the most publications (see Table 3). The lines stand for the co-authorship relationship. The thicker the line, the more 
co-authorships that existed between the two countries linked by it. Figure 4 shows that the United States of America, Canada, New Zealand, and Australia formed a cooperation cluster. It also shows that Spain and China cooperated, while the United Kingdom, the Netherlands, and Sweden formed a cooperation cluster.

Table 3. Top countries contributing to the OEP literature.

\begin{tabular}{cccc}
\hline Rank & Country & Documents & Citations \\
\hline 1 & United Kingdom & 38 & 269 \\
2 & Spain & 21 & 84 \\
3 & Australia & 20 & 96 \\
4 & United States of & 18 & 96 \\
5 & America & 12 & 93 \\
6 & Canada & 9 & 73 \\
7 & South Africa & 8 & 31 \\
8 & China & 7 & 21 \\
9 & Colombia & 7 & 50 \\
10 & New Zealand & 4 & 141 \\
11 & Ireland & 4 & 39 \\
12 & Netherlands & 4 & 19 \\
13 & Philippines & 4 & 18 \\
14 & Sweden & 4 & 3 \\
\hline
\end{tabular}

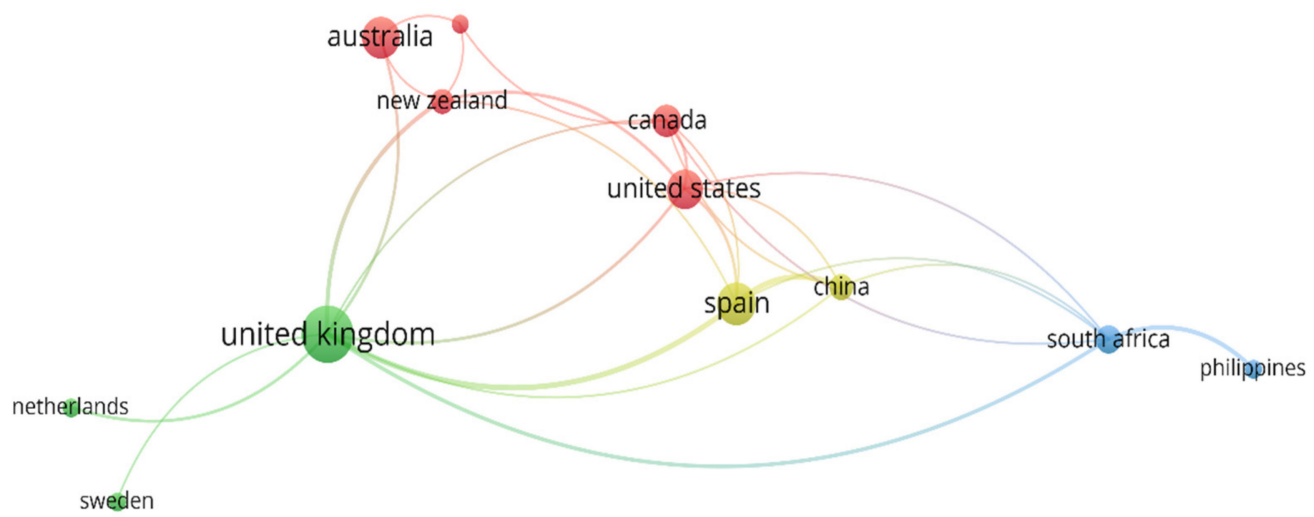

Figure 4. Visualisation of co-authorships by country.

When examining the organisations that contributed to the OEP literature, it was found that the literature contained contributions from 242 organisations. Table 4 presents the organisations that contributed at least three documents. The Open University of the United Kingdom provided the most contributions (seven publications), followed by the University of Southern Queensland, Australia (five publications), and Universidad de la Sabana, Colombia (five publications).

The literature contains contributions from 314 authors. Table 5 presents the authors who contributed at least four documents. The top contributors were Fabio Nascimbeni (8 documents) and Daniel Burgos (7 documents), affiliated with a Spanish university, followed by Carina Bossu (7 documents), affiliated with the Open University of the UK, and Ahmed Tlili (6 documents), affiliated with a Chinese university.

Figure 5 maps the co-authorship between authors who had published at least four documents on OEP (see Table 5). This mapping used the fractional counting method. The colour, circle size, font size and thickness of the connecting lines indicate the strength of the relationship between the authors. Related authors, indicated by the same colour, were those who were frequently listed together. For instance, Figure 5 shows that the authors Ahmed Tlili and Ronghuai Huang, both with the same Chinese affiliation, cooperated, and both of them cooperated with Daniel Burgos and Fabio Nascimbeni (both from the same 
Spanish affiliation). This was consistent with the results from Figure 4, which shows that Spain and China cooperated. Some authors, such as Andres Chiappe, contributed to the OEP literature without cooperating with any other authors.

Table 4. Top organisations that contributed to the OEP literature.

\begin{tabular}{cccc}
\hline Rank & Organisation & Documents & Citations \\
\hline 1 & Open University, United Kingdom & 7 & 33 \\
2 & University of Southern Queensland, Australia & 5 & 28 \\
3 & Universidad de la Sabana, Colombia & 5 & 16 \\
4 & Kwantlen Polytechnic University, Canada & 4 & 33 \\
5 & University of Tasmania, Australia & 4 & 19 \\
6 & University of the Philippines Open University, Philippines & 4 & 19 \\
7 & Smart Learning Institute of Beijing Normal University, China & 3 & 15 \\
8 & University of Cape Town, South Africa & 3 & 15 \\
9 & Unir Ited, Universidad Internacional de la Rioja (UNIR), Spain & 3 & 13 \\
\hline
\end{tabular}

Table 5. Top authors that contributed to the OEP literature.

\begin{tabular}{cccc}
\hline Rank & Author & Documents & Number of Citations \\
\hline 1 & Fabio Nascimbeni & 8 & 36 \\
2 & Daniel Burgos & 7 & 35 \\
3 & Carina Bossu & 7 & 20 \\
4 & Ahmed Tlili & 6 & 26 \\
5 & Adrian Stagg & 6 & 20 \\
6 & Andres Chiappe & 6 & 18 \\
7 & Ronghuai Huang & 5 & 26 \\
8 & Allison Littlejohn & 4 & 28 \\
9 & Som Naidu & 4 & 27 \\
10 & Ting-Wen Chang & 4 & 26 \\
11 & Cheryl Hodgkinson- & 4 & 19 \\
12 & Williams & 4 & 19 \\
13 & Patricia Arinto & 4 & 6 \\
\hline
\end{tabular}

chiappe a.

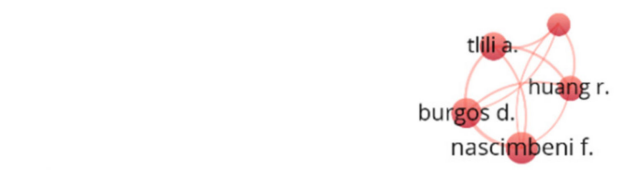

Figure 5. Network visualisation map of OEP research co-authorships. 
3.3. What Were the Most Frequently Used Research Methods and Data Collection Techniques by Researchers in OEP?

The majority of distance education research can be classified broadly as quantitative, qualitative, or mixed methods, which employed both quantitative and qualitative approaches. For this review, the research methods were classified as quantitative, qualitative, mixed methods, or other [31]. Articles that used statistical analysis were classified as quantitative, from simple methods, such as chi-square analysis, to multivariate techniques. Qualitative studies were data-based articles that did not quantify data beyond frequency counts. Included in this category were case studies, interpretive ethnographies, grounded theory, and phenomenological studies. Other articles were usually descriptive, not databased, theoretical, or conceptual papers. Figure 6 presents the research methods that were adopted by researchers in the OEP field. Specifically, it is seen that most of the studies used qualitative analyses that were done after collecting data using interviews or observations.

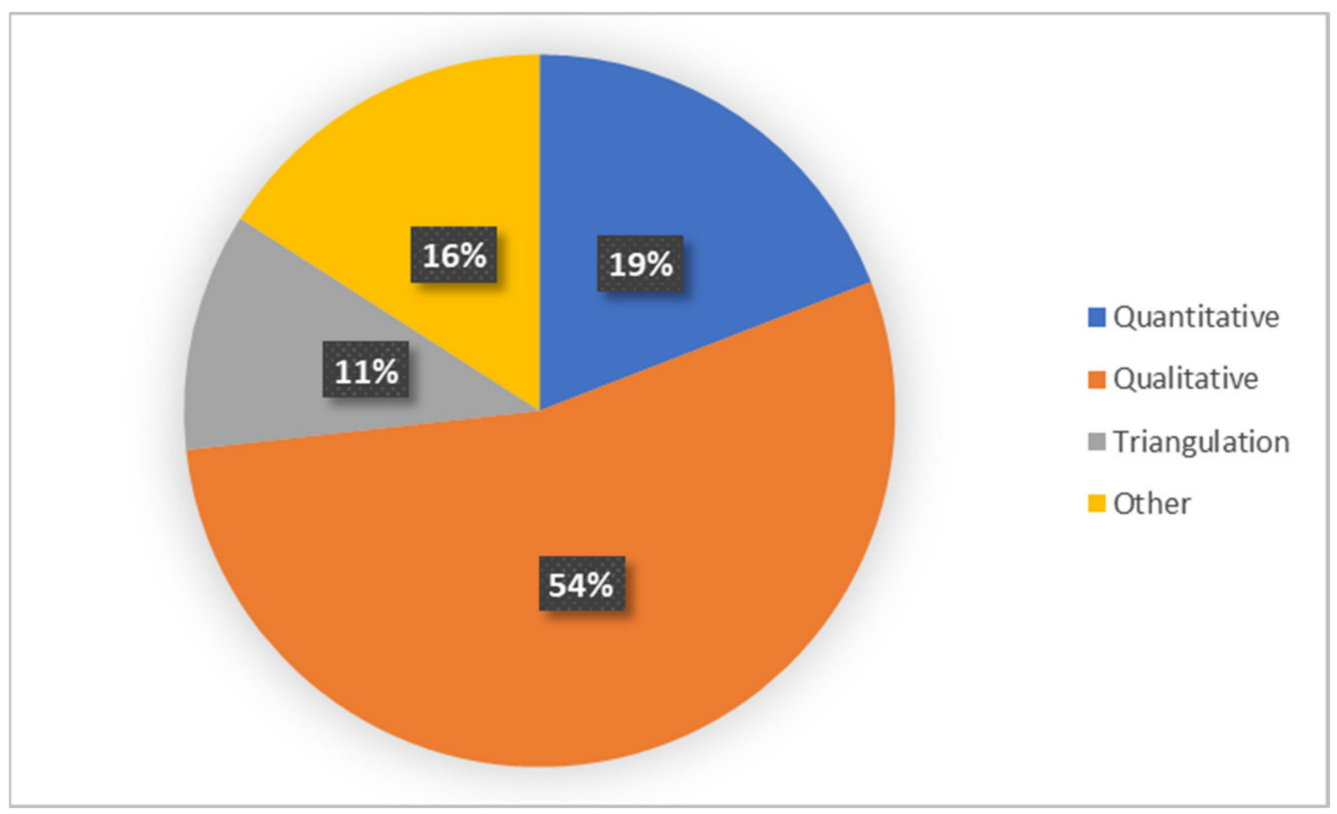

Figure 6. Research methods in the OEP field.

3.4. What Were the Most Frequently Used Terms in the Keywords, Abstracts, and Titles of OEP Research Studies in the Web of Science and Scopus?

The OEP research studies used 502 different keywords. Table 6 presents the keywords that appeared at least six times. The most frequently used keywords were "open educational resources" and "open educational practices", followed by "higher education", "open education", "open pedagogy", and "collaboration".

Figure 7 presents a network visualisation of the keywords that appeared at least six times (see Table 6). The colour, circle size, font size, and thickness of the connecting lines represent relationships with other keywords. Keywords with the same colour were frequently listed together. Several keywords were frequently mentioned together. For example, "open educational practices", "open educational resources", and "mooc'" were frequently mentioned together (blue cluster). Additionally, "open educational practices (oep)", "open educational resources (oer)", "open textbooks", and "open pedagogy" were frequently mentioned together (green cluster). Finally, "open educational practice", "openness", "collaboration", and "social media" were frequently mentioned together (red cluster). 
Table 6. Top keywords used in OEP research studies.

\begin{tabular}{ccc}
\hline Rank & Keywords & Number of Occurrences \\
\hline 1 & open educational resources & 55 \\
2 & open educational practices & 51 \\
3 & higher education & 27 \\
5 & open educational practice & 24 \\
6 & open education & 24 \\
7 & oer & 17 \\
8 & education & 14 \\
9 & oep & 10 \\
10 & open pedagogy & 10 \\
11 & open educational practices (oep) & 8 \\
12 & open educational resources (oer) & 8 \\
13 & collaboration & 8 \\
14 & distance education & 8 \\
15 & openness & 7 \\
16 & social media & 7 \\
17 & teaching & 7 \\
18 & mooc & 7 \\
19 & educational technology & 7 \\
20 & open textbooks & 6 \\
\hline
\end{tabular}

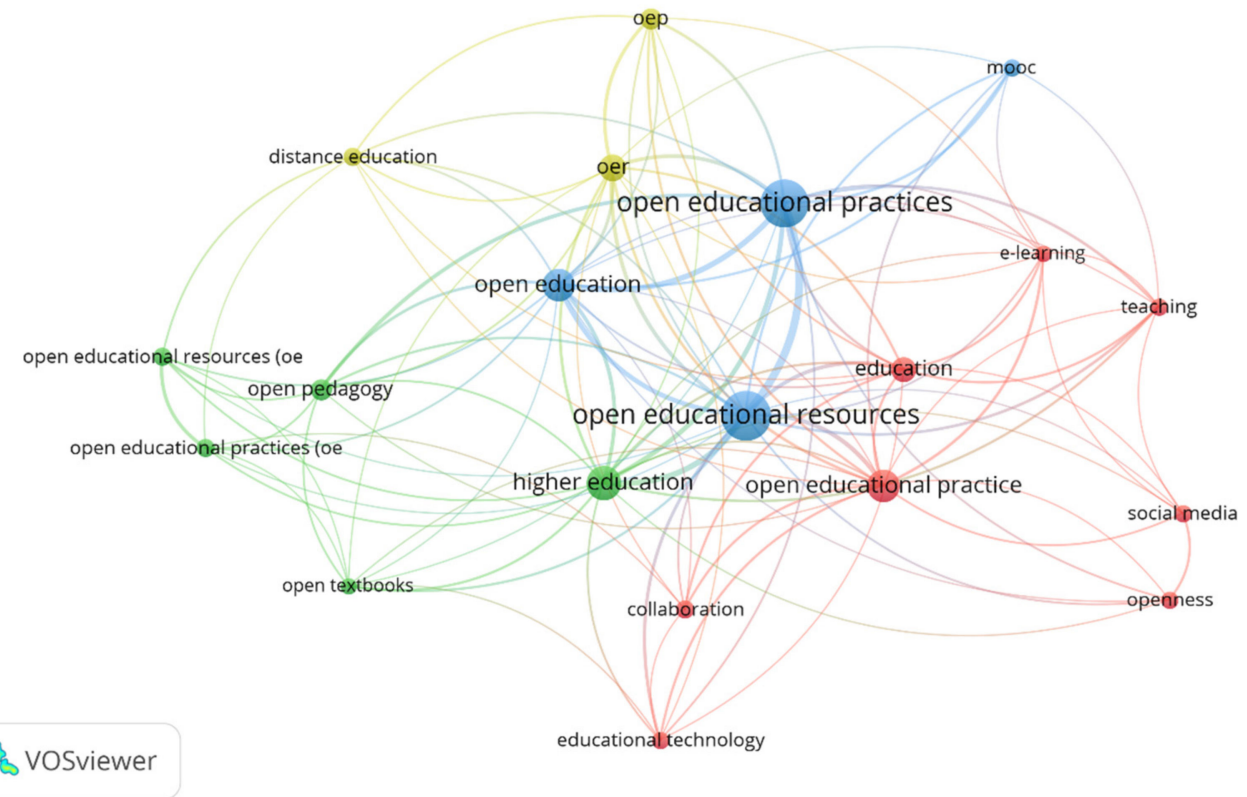

Figure 7. Network visualisation map of keywords.

To identify the focus and trends of OEP research, the co-occurrence of terms in both abstracts and titles was analysed using binary counting. The threshold for including a term in the analysis was a minimum of 10 occurrences. Out of 3,532 terms, only 56 terms met this threshold. However, only 35 were selected and considered based on a relevance score calculated using VOSviewer. The relevance score is useful for identifying the more informative terms that better represent specific topics [32]. The resulting co-occurrence network map is shown in Figure 8, where four final clusters are presented in different colours (red, green, yellow, and blue). The sizes of the labels and circles depend on the number of occurrences. Lines identify major links between terms, and their thickness and the distance between the terms represent the association strength. It should be noted that some term labels are not shown because of the scale (e.g., the "educational resource" circle overlaps the "educational practice" circle). 


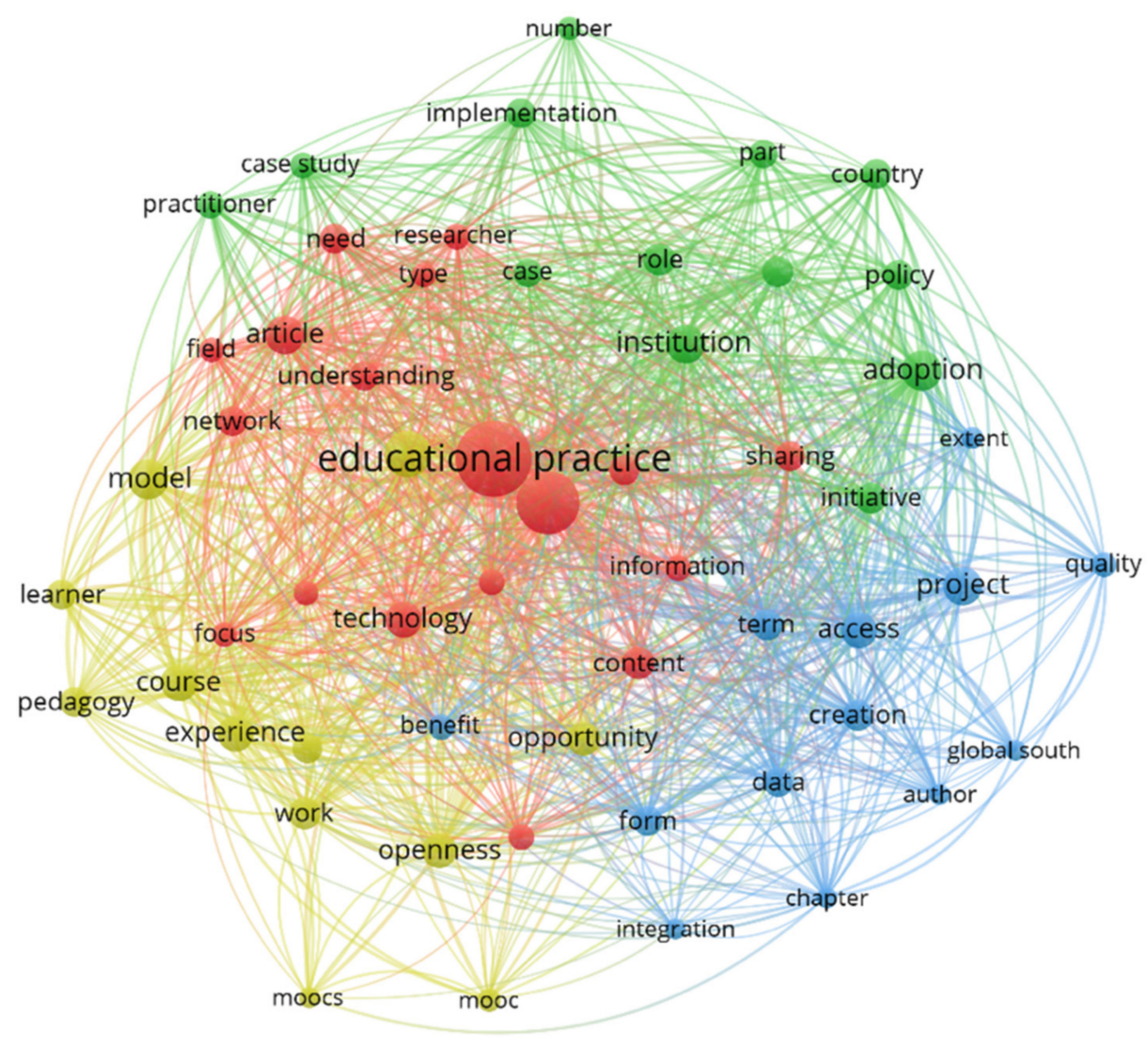

Figure 8. Co-occurrence network map of terms found in titles and abstracts.

As shown in Figure 8, four clusters were obtained. The blue cluster seemed to focus on the design process, with terms like "creation", "integration", "quality", "access", and "data". The green cluster seemed to focus on the targeted stakeholders, covering terms like "institution", "practitioner", "policy", and "role". The yellow cluster seemed to focus on the open educational practices, with terms like "open educational practice", "openness", "pedagogy", "mooc", "model", and "learner". Finally, the red cluster focused on the infrastructure to support OEP, with terms like "open educational resources", "technology", "content", "information", "sharing", and "need".

\section{Discussion}

This study was motivated by the fact that several research studies and organisations (e.g., UNESCO) called for wider implementation of OEP, as they can enhance learning outcomes, ensure inclusive education and contribute to the United Nations' Sustainable Development Goal 4 [33]. However, several questions related to OEP are still unanswered [13]. To address this issue, we conducted a bibliometric mapping analysis of OEP literature to evaluate research articles and identify their trends and patterns so as to better understand the OEP field. The results are discussed separately for each research question.

4.1. What Was the Distribution of OEP Research Studies in Terms of Publication Year, Document Type, Language, and Publication Venue in the Web of Science and Scopus?

The time trend analysis indicated that research on OEP started in 2007 when the first declaration about open education using OER was launched [34]. The number of published OEP studies has been slowly increasing each year. Since 2012, the pace of the increase has been picking up. This could be because of the 2012 Paris OER Declaration, held at the UNESCO headquarters, which urged governments around the world to release, as OER, all teaching, learning, and research materials developed with public funds [35]. Figure 1 shows peaks in 2017 and 2020 when the greatest numbers of publications related to OEP 
were published. A possible explanation was that in 2017, UNESCO [36] presented the Ljubljana OER Action Plan, which focused on concrete OER-based pedagogical practices and actions to enhance lifelong learning and accessibility and contribute to the Sustainable Development Goals (SDG4). Similarly, by the end of 2019, UNESCO [2] released the OER Recommendation as an international standard-setting framework, which focused on five areas: (1) capacity building; (2) developing supportive policy; (3) effective, inclusive, and equitable access to quality OER; (4) nurturing the creation of sustainability models for OER; and (5) fostering and facilitating international cooperation. Therefore, it can be concluded that OER policies and initiatives were catalysts for OEP research and application.

While the interest in OEP has clearly increased over time, when we compared our findings to the bibliometric analysis findings on OER from the paper by Wang et al. [17], we found that less research was being done on OEP than on OER. Therefore, such a view indicates that more specific OEP initiatives should be launched to facilitate OEP implementation and research. For instance, as well as efforts to increase the awareness of OEP, more training should be provided to help teachers acquire the OEP competencies that are needed to design their OEP-based courses. Zhang et al. [37], for instance, designed an OEP-based course for teaching family education and reported that specific training had to be provided for teachers to enhance their skills in (1) being effective facilitators of the learning process while using an OEP-based course and (2) designing diversified engaging learning activities that match the needs of all learners (e.g., shy learners).

The analysis revealed that most authors published their OEP studies in peer-reviewed journals. This could be explained by the fact that journals allowed open-access publishing (even at no charge), which is consistent with the OER and OEP principles. On the other hand, most conferences did not provide this possibility. We found that Distance Education, International Review of Research in Open and Distributed Learning, Open Praxis, and Journal of Interactive Media in Education were the most frequently targeted journals for OEP studies. These journals could have been chosen for two reasons: (1) These journals are fully openaccess with no article processing charge and free for both authors and readers (except for Distance Education, which does, however, also provide open access possibilities; it should be further noted that there is a special issue on OEP by Koseoglu et al. [13]). (2) These journals are supported by well-known editors or publishers in the field of OER. For instance, Open Praxis is published by the International Council for Open and Distance Education (ICDE). Meanwhile, the editors of Distance Education and International Review of Research in Open and Distributed Learning are, respectively, Som Naidu and Rory McGreal, who are leading researchers in the field of open education (including OER).

\subsection{Who Were the Major Contributors to the OEP Literature in the Web of Science and Scopus?}

Our findings showed that the United Kingdom produced the greatest number of published OEP research studies, followed by Spain, Australia, and the United States. When comparing our findings to the findings of Wang et al. [17] regarding the contributors to OER literature, the United Kingdom, Spain, and the USA were listed in the top four contributors to both the OER and OEP literature. However, while the United Kingdom was in third place as a contributor to OER literature, it was in first place as a contributor to OEP literature. Additionally, while Romania was in fourth place as a contributor to OER literature [17], it was not on the OEP contributor list (see Table 3). Therefore, some countries seemed to have shifted their focus from OER to OEP earlier than others. This may have been because several countries had already managed to adopt OER in universities and therefore moved on to focusing on OEP for better learning experiences and outcomes. However, others countries are still struggling to facilitate OER adoption and thus it is too early for them to focus on OEP. Therefore, the adoption of OER is the first essential stepping stone to supporting OEP. Interestingly, this was also observed when discussing the first research question (see Section 4.1), as OER policies were catalysts for OEP research. It is also worth noting that the contributions mostly came from Global North countries 
with less interest from Global South countries, which was a pattern that was also reported by Kanwar et al. [38] and Bozkurt et al. [39].

This study also revealed that the Open University of the United Kingdom made more contributions than any other organisation, followed by the University of Southern Queensland, Australia, and Universidad de la Sabana, Colombia. Wang et al. [17] also found that the Open University of the UK was the most prolific contributor to the OER literature. It seems that the Open University of the UK is one of the leaders in the field of both OER and OEP. This could be because the Open University of the UK was one of the leading open universities, as well as being one of the first organisations to develop an open education platform, namely, OpenLearn, which provides access to course content from the entire range of its subject areas [40]. This OER platform gave educators a solid foundation for implementing OEP. Interestingly, some universities, such as the University of Southern Queensland, Australia, and the Universidad de la Sabana, Colombia, which are among the top contributors to the OEP literature, were not listed as the top contributors to the OER literature [17]. This further shows that there was a growing interest in and adoption of OEP by universities.

It was also identified that there was on-going international cooperation regarding OEP; however, its scale is limited. This implies that there is a shortage of perspectives regarding OEP implementation from diverse economic, cultural, and institutional backgrounds, despite the potential of OER to cross boundaries. For instance, some cultures believe that teaching materials should come from the "elite", and students cannot be co-creators of the teaching materials. Therefore, a strategy for the internationalisation of OEP implementation is needed to further foster international cooperation.

\subsection{What Were the Most Frequently Used Research Methods and Data Collection Techniques by Researchers in OEP?}

The obtained results (see Figure 6) showed that most of the OEP studies used qualitative analysis (54\%), followed by quantitative analysis (19\%). In particular, most of the studies relied on surveys and interviews for data collection. However, these instruments can only obtain students' subjective perceptions, which can be biased or faked easily [41]. No reviewed OEP study focused on analysing students' learning traces or behaviours to gain more concrete insight into how different stakeholders (e.g., teachers or students) used or perceived OEP. In this context, it is suggested that open data, openly licensed, interoperable, and re-usable datasets be designed and used to learn more about how OEP are being used and perceived in different universities. Atenas, Havemann, and Priego [42] stated that open data could be crucial for effectively analysing and interrupting data to evaluate a given project.

\subsection{What Were the Most Frequently Used Terms in the Keywords, Abstracts, and Titles of OEP} Research Studies in the Web of Science and Scopus?

Unsurprisingly, the terms "open educational resources" and "open educational practices" occurred most frequently, followed by "higher education". This implied that most of the studies that focused on the application of OEP were in the higher education context. The reason for this could be that the OER movement began in the higher education context when the Massachusetts Institute of Technology (MIT) OpenCourseWare initiative offered high-quality open educational resources to the public. These findings also showed that more research is needed to extend the application of OEP from higher education to other contexts, such as $\mathrm{K}-12$ education and vocational education.

Additionally, we analysed the keywords to see which ones occurred together. Each combination revealed a specific trend related to OEP:

(1) Keywords "open educational practices (oep)", "open educational resources (oer)", "open textbooks", and "open pedagogy" OR "open educational practices", "open educational resources", and "mooc": This combination showed that the authors focused on applying open pedagogy as an open educational practice with the use of open 
textbooks or MOOCs. Open pedagogy allows students to contribute to the teaching process using OER by, for instance, adding to or updating the teaching content $[43,44]$. This could be achieved via the use of open textbooks, where the students can add more content and assignments for each chapter. For instance, Wiley [44] argues that "disposable assignments", meaning assignments that are forgotten or never used after the course, do not benefit anyone. Therefore, they should be replaced with activities that both teachers and learners can work on and that can benefit others. For instance, the use of open textbooks allows the content to be updated constantly and benefits future students and teachers [25]. While MOOCs are not fully considered OER [45], they can be built using OER. Therefore, students can contribute to enriching the content of a given MOOC using OER.

(2) Keywords "open educational practice", "openness", "collaboration", and "social media": This combination showed that the authors focused on applying open collaboration as an open educational practice through the use of social media. Hegarty [43] stated that in OEP, learning is facilitated by peers. Therefore, it is possible to use social media tools to build open learning communities where the students can openly exchange ideas, lead discussions, and collaborate on different tasks. This can foster learning interaction and enhance learning outcomes [25].

In line with the trends revealed above, Huang et al. [25] recently reviewed OEP definitions in the literature and identified three possible OEP trends: open assessment, open collaboration, and open teaching/pedagogy. We found that the literature covered only two trends (open pedagogy and open collaboration), and more investigation is needed about open assessment (i.e., teachers should allow learners to evaluate one another), as this can emphasise reflective practices and improve learning outcomes [25].

The analysis of term co-occurrence in titles and abstracts revealed that one of the researchers' areas of focus is OEP design, which is essential for the successful implementation of OEP. Huang et al. [25] pointed out that schools and universities might find it challenging to adapt their pedagogies to OEP. They also mention that teachers fear losing control over the learning process when they invite students to be co-creators of the teaching content. Therefore, more research is needed on the successful design of OEP. Furthermore, we found little research on the use of OEP for students with disabilities, although several studies have pointed out that OER can foster inclusive education. Therefore, future research should also cover inclusive open educational practices for students with disabilities.

\section{Conclusions, Limitations and Implications}

This study used bibliometric mapping analysis to conduct a comprehensive overview of OEP literature. The analysis of the evolution of OEP research studies and collaborations between authors in terms of a series of categories (i.e., number of published studies per year, publication venues, languages, contributing countries, organisations, authorship, keywords, and document titles and abstracts) indicated the broad trends of OEP. We found that research on OEP began in 2007 and has continuously grown since then. However, less research was done on OEP than on OER, suggesting that more OEP research is needed. Additionally, international cooperation in OEP research was found to be limited, suggesting a need for understanding educational practices across different cultures, and for specialised strategies to encourage stronger international participation. Furthermore, more attention should be paid to inclusive OEP for students with disabilities.

This study has some limitations that should be acknowledged and further researched. For instance, we used specific keywords and focused on only two databases, namely, the WoS and Scopus. Therefore, our findings may be limited. Additionally, this study did not consider the number of citations as a factor to analyse.

Despite these limitations, this study provides a solid foundation for understanding the trends and the current state of the art in OEP research and publications. This study extended and complemented previous findings in the OEP literature by using bibliometric methods to identify future directions for OEP research. This can help to fill the educational 
gaps in the applications of OEP, as well as facilitate the adoption of open education in general and OEP in particular, thereby contributing to the United Nation's [46] Sustainable Development Goals (SDG4). Focusing efforts on cultural differences in education could help to internationalise the applied open educational practices and facilitate the reapplication of OEP in different cultural contexts. This will help to reach educational goals worldwide and ensure that everyone benefits from OEP.

Author Contributions: Conceptualization, S.M.; Data curation, R.H.; Formal analysis, A.T.; Methodology, R.H. and R.C.S.; Validation, S.M.; Visualization, D.B. and A.B.; Writing-original draft, A.T.; Writing-review \& editing, D.B., R.C.S. and A.B. Each author contributed evenly to this manuscript. All authors have read and agreed to the published version of the manuscript.

Funding: This research received no external funding.

Data Availability Statement: Not applicable.

Conflicts of Interest: The authors declare no conflict of interest.

\section{References}

1. Baraniuk, R.G. Challenges and opportunities for the open education movement: A Connexions case study. In Opening Up Education: The Collective Advancement of Education through Open Technology, Open Content, and Open Knowledge; Iiyoshi, T., Vijay Kumar, M.S., Eds.; MIT Press: Cambridge, MA, USA, 2008; pp. 229-246.

2. UNESCO. Recommendation on Open Educational Resources (OER). Available online: http://portal.unesco.org/en/ev.phpURL_ID=49556\&URL_DO=DO_TOPIC\&URL_SECTION=201.html (accessed on 12 July 2021).

3. Hilton, J.; Larsen, R.; Wiley, D.; Fischer, L. Substituting open educational resources for commercial curriculum materials: Effects on student mathematics achievement in elementary schools. Res. Math. Educ. 2019, 21, 60-76. [CrossRef]

4. Fischer, L.; Hilton, J.; Robinson, T.J.; Wiley, D.A. A multi-institutional study of the impact of open textbook adoption on the learning outcomes of post-secondary students. J. Comput. High. Educ. 2015, 27, 159-172. [CrossRef]

5. Zhang, X.; Tlili, A.; Nascimbeni, F.; Burgos, D.; Huang, R.; Chang, T.-W.; Jemni, M.; Khribi, M.K. Accessibility within open educational resources and practices for disabled learners: A systematic literature review. Smart Learn. Environ. 2020, 7, 1-19. [CrossRef]

6. Cronin, C. Openness and Praxis: Exploring the Use of Open Educational Practices in Higher Education. Int. Rev. Res. Open Distrib. Learn. 2017, 18, 15-34. [CrossRef]

7. OLCOS Roadmap. Open Educational Practices and Resources. Available online: https://www.olcos.org/cms/upload/docs/ olcos_roadmap.pdf (accessed on 12 July 2021).

8. Andrade, A.; Ehlers, U.D.; Caine, A.; Carneiro, R.; Conole, G.; Kairamo, A.-K.; Koskinen, T.; Krestschmer, T.; Moe-Pryce, N.; Mundin, P.; et al. Beyond OER: Shifting Focus to Open Educational Practices: OPAL Report 2011. Available online: https://www.researchgate.net/publication/259597164_Beyond_OER_-_Shifting_Focus_to_Open_Educational_Practices_ OPAL_Report_2011 (accessed on 12 July 2021).

9. Wiley, D.; Hilton, J.L., III. Defining OER-Enabled Pedagogy. Int. Rev. Res. Open Distrib. Learn. 2018, 19, 133-147. [CrossRef]

10. Ehlers, U.D. Extending the territory: From open educational resources to open educational practices. J. Open Flex. Distance Learn. 2011, 15, 1-10.

11. Huang, R.; Liu, D.; Tlili, A.; Knyazeva, S.; Chang, T.W.; Zhang, X.; Holotescu, C. Guidance on Open Educational Practices During School Closures: Utilizing OER under COVID-19 Pandemic in Line with UNESCO OER Recommendation; Smart Learning Institute of Beijing Normal University: Beijing, China, 2020.

12. Weller, M.; Jordan, K.; Devries, I.; Rolfe, V. Mapping the open education landscape: Citation network analysis of historical open and distance education research. Open Prax. 2018, 10, 109-126. [CrossRef]

13. Koseoglu, S.; Bozkurt, A.; Havemann, L. Critical Questions for Open Educational Practices. Distance Educ. 2020, 41, 153-155. [CrossRef]

14. Yilmaz, R.M.; Topu, F.B.; Tulgar, A.T. An examination of the studies on foreign language teaching in pre-school education: A bibliometric mapping analysis. Comput. Assist. Lang. Learn. 2019, 1-24. [CrossRef]

15. Heersmink, R.; Hoven, J.V.D.; van Eck, N.J.; Berg, J.V.D. Bibliometric mapping of computer and information ethics. Ethic-Inf. Technol. 2011, 13, 241-249. [CrossRef]

16. Vogel, R.; Masal, D. Public Leadership: A review of the literature and framework for future research. Public Manag. Rev. 2015, 17, 1165-1189. [CrossRef]

17. Wang, X.; Liu, M.; Li, Q.; Gao, Y. A bibliometric analysis of 15 years of research on open educational resources. In Proceedings of the 25th International Conference on Computers in Education, Christchurch, New Zealand, 4-8 December 2017.

18. Zancanaro, A.; Ramos, F.; Todesco, J.L. A bibliometric mapping of open educational resources. Int. Rev. Res. Open Distrib. Learn. 2015, 16, 1-23. [CrossRef] 
19. Wahid, R.; Ahmi, A.; Alam, A.F. Growth and collaboration in massive open online courses: A bibliometric analysis. Int. Rev. Res. Open Distrib. Learn. 2020, 21, 292-322. [CrossRef]

20. Koseoglu, S.; Bozkurt, A. An exploratory literature review on open educational practices. Distance Educ. 2018, 39, 441-461. [CrossRef]

21. Parreño, J.M.; Ibáñez, E.M.; Arroyo, A.A. The use of gamification in education: A bibliometric and text mining analysis. J. Comput. Assist. Learn. 2016, 32, 663-676. [CrossRef]

22. Aria, M.; Cuccurullo, C. bibliometrix: An R-tool for comprehensive science mapping analysis. J. Informetr. 2017, 11, 959-975. [CrossRef]

23. Broadus, R.N. Toward a definition of "bibliometrics". Science 1987, 12, 373-379. [CrossRef]

24. Zancanaro, A.; Erpen, J.G.; Santos, J.L.S.; Steil, A.V.; Todesco, J.L. Mapeamento da produção científica sobre memória organizacional e ontologies. Perspect. Ciência Inf. 2013, 18, 43-65. [CrossRef]

25. Huang, R.; Tlili, A.; Chang, T.-W.; Zhang, X.; Nascimbeni, F.; Burgos, D. Disrupted classes, undisrupted learning during COVID-19 outbreak in China: Application of open educational practices and resources. Smart Learn. Environ. 2020, 7, 1-15. [CrossRef]

26. Harzing, A.-W.; Alakangas, S. Google Scholar, Scopus and the Web of Science: A longitudinal and cross-disciplinary comparison. Scientometrics 2016, 106, 787-804. [CrossRef]

27. Van Eck, N.J.; Waltman, L. Software survey: VOSviewer, a computer program for bibliometric mapping. Scientometrics 2009, 84, 523-538. [CrossRef]

28. Tlili, A.; Burgos, D.; Altinay, F.; Altinay, Z.; Huang, R.; Jemni, M. Remote Special Education during COVID-19: A Combined Bibliometric, Content and Thematic Analysis. In Proceedings of the 2021 International Conference on Advanced Learning Technologies (ICALT), Tartu, Estonia, 12 July 2021; pp. 325-329.

29. Garrigos-Simon, F.J.; Narangajavana-Kaosiri, Y.; Lengua-Lengua, I. Tourism and sustainability: A bibliometric and visualization analysis. Sustainability 2018, 10, 1976. [CrossRef]

30. Goerlandt, F.; Li, J.; Reniers, G. The landscape of risk communication research: A scientometric analysis. Int. J. Environ. Res. Public Health 2020, 17, 3255. [CrossRef] [PubMed]

31. Grant, L.; Ward, K.B.; Rong, X.L. Is there an association between gender and methods in sociological research? Am. Sociol. Rev. 1987, 52, 856. [CrossRef]

32. Van Eck, N.J.; Waltman, L. VOSviewer Manual. Available online: https://www.vosviewer.com/documentation/Manual_ VOSviewer_1.6.8.pdf (accessed on 29 April 2021).

33. Perryman, L.-A.; Arcos, B.D.L. Women's empowerment through openness: OER, OEP and the sustainable development goals. Open Prax. 2016, 8, 163-180. [CrossRef]

34. Cape Town Open Education Declaration: Unlocking the Promise of Open Educational Resources. Available online: www. capetowndeclaration.org/read-the-declaration (accessed on 18 July 2021).

35. The Paris OER Declaration 2012. Available online: https://en.unesco.org/oer/paris-declaration (accessed on 18 July 2021).

36. Second World OER Congress: Ljubljana OER Action Plan 2017. Available online: https://en.unesco.org/sites/default/files/ ljubljana_oer_action_plan_2017.pdf (accessed on 18 July 2021).

37. Zhang, X.; Tlili, A.; Huang, R.; Chang, T.; Burgos, D.; Yang, J.; Zhang, J. A case study of applying open educational practices in higher education during COVID-19: Impacts on learning motivation and perceptions. Sustainability 2020, 12, 9129. [CrossRef]

38. Kanwar, A.; Kodhandaraman, B.; Umar, A. Toward sustainable open education resources: A perspective from the global south Am. J. Distance Educ. 2010, 24, 65-80. [CrossRef]

39. Bozkurt, A.; Koseoglu, S.; Singh, L. An analysis of peer reviewed publications on openness in education in half a century: Trends and patterns in the open hemisphere. Australas. J. Educ. Technol. 2019, 35, 78-97. [CrossRef]

40. Open Learning-OpenLearn-Open University. Available online: https://www.open.edu/openlearn/ (accessed on 20 July 2021).

41. Tlili, A.; Essalmi, F.; Jemni, M.; Chen, N.-S. Role of personality in computer based learning. Comput. Hum. Behav. 2016, 64, 805-813. [CrossRef]

42. Atenas, J.; Havemann, L.; Priego, E. Open data as open educational resources: Towards transversal skills and global citizenship. Open Prax. 2015, 7, 377-389. [CrossRef]

43. Hegarty, B. Attributes of open pedagogy: A model for using open educational resources. Educ. Technol. 2015, 3, 3-13.

44. Wiley, D. What is Open Pedagogy? 2013. Available online: https://opencontent.org/blog/archives/2975 (accessed on 20 July 2021).

45. Stracke, C.M.; Downes, S.; Conole, G.; Burgos, D.; Nascimbeni, F. Are MOOCs Open Educational Resources? A literature review on history, definitions and typologies of OER and MOOCs. Open Prax. 2019, 11, 331-341. [CrossRef]

46. United Nations. Sustainable Development Goals-SDG. 2021. Available online: https://www.un.org/sustainabledevelopment/ education/ (accessed on 20 July 2021). 